\title{
One-Dimensional and Two-Dimensional ZnO Nanostructured Materials on a Plastic Substrate and Their Field Emission Properties
}

\author{
Debabrata Pradhan, ${ }^{\dagger}$ Mukul Kumar,, Yoshinori Ando,, and Kam Tong Leung ${ }^{*, \dagger}$ \\ WATLab and Department of Chemistry, University of Waterloo, Waterloo, Ontario, N2L 3G1, Canada, and \\ Department of Materials Science and Engineering, Meijo University, Nagoya 468-8502, Japan
}

Received: January 28, 2008; In Final Form: March 20, 2008

\begin{abstract}
One-dimensional $\mathrm{ZnO}$ nanopillars of diameter 80-120 nm and two-dimensional nanowalls of thickness 100$300 \mathrm{~nm}$ are electrochemically grown at $70{ }^{\circ} \mathrm{C}$ on a flexible polyester substrate. The low turn-on electric fields measured at a current density of $1 \mu \mathrm{A} / \mathrm{cm}^{2}$ for nanopillars $(1.2 \mathrm{~V} / \mu \mathrm{m})$ and nanowalls $(2.2 \mathrm{~V} / \mu \mathrm{m})$ illustrate their superior field emission properties to most of the reported $\mathrm{ZnO}$ nanostructures. The present method of direct electrodeposition of $\mathrm{ZnO}$ on plastic without the need of template or catalyst offers a low-cost technique for fabricating field emission devices on flexible substrates for large-area display and other technologies.
\end{abstract}

\section{Introduction}

One-dimensional (1D) nanostructures have been generally found to be excellent electron field emitters because of their high aspect ratios, which enable emission at a low turn-on field. Among several 1D metallic and semiconducting nanomaterials, $\mathrm{ZnO}$ has exhibited promising field emission (FE) properties. ${ }^{1-5}$ Being an oxide material, $\mathrm{ZnO}$ is inherently stable at high temperature and resistant to further oxidation, both of which are advantageous for FE applications. The FE properties of 1D $\mathrm{ZnO}$ nanostructures such as nanowires, nanoneedles, nanopins, and nanobelts have been recently reported..$^{1-5}$ However, nearly all of these 1D nanostructures are synthesized on expensive silicon or sapphire substrates by using thermal evaporation methods at a temperature well above $550{ }^{\circ} \mathrm{C}$ and often in the presence of catalysts. ${ }^{1-5}$ It would therefore be of great practical interest to develop a lower temperature technique to synthesize $\mathrm{ZnO}$ nanostructures on lower cost substrates such as plastics for large-area applications. To date, only a few efforts have been made to characterize the $\mathrm{FE}$ properties of $\mathrm{ZnO}$ nanostructures obtained by low-temperature methods, ${ }^{6-10}$ including the $\mathrm{ZnO}$ nanowire arrays synthesized by employing templates. ${ }^{6,7} \mathrm{Al}-$ though $\mathrm{ZnO}$ nanowires have also been grown successfully without templates by using an electrochemical technique,,${ }^{8,11-13}$ only one study has reported the FE properties of the electrodeposited material (with a high turn-on field). ${ }^{8}$

In the present work, we demonstrate the successful growth of two different $\mathrm{ZnO}$ nanostructures, nanopillars (1D) and nanowalls (2D), on a plastic substrate by using electrodeposition at low temperature $\left(70^{\circ} \mathrm{C}\right)$ without templates. The present result is especially relevant to not only field emission devices but also solar cells and flexible electronics because of the inexpensive polyester (PET) substrate and the low growth temperature. Furthermore, these electrodeposited nanopillars and nanowalls

* To whom correspondence should be addressed. E-mail: tong@ uwaterloo.ca.

$\dagger$ University of Waterloo.

$\doteqdot$ Meijo University. exhibit a turn-on field that is considerably lower (better) than that of the other electrochemically synthesized $\mathrm{ZnO}$ nanostructures $^{8}$ and comparable to the best $1 \mathrm{D} \mathrm{ZnO}$ nanostructures synthesized at considerably higher temperature by the thermal evaporation methods. ${ }^{14,15}$ The high temperature requirement of the latter methods rules out the use of plastics as the substrate material.

\section{Experimental Details}

The $\mathrm{ZnO}$ nanopillars and nanowalls were electrodeposited on PET substrates $(0.2 \mathrm{~mm}$ thick) coated with an indium oxide $\left(\mathrm{In}_{2} \mathrm{O}_{3}\right)$ layer with a sheet resistivity of $<10 \Omega$, obtained commercially from Delta Technologies Ltd. (Stillwater, MN). Similar nanostructures could also be obtained on PET substrates sputter-coated with a 10-nm-thick gold layer. It should be noted that the $\operatorname{In}_{2} \mathrm{O}_{3}$ or gold layer is used to provide a conducting surface for the electrodeposition and these conducting layers do not function as a catalyst. Indeed, a considerably higher temperature is needed in order for gold to act as a catalyst. ${ }^{16,17}$ The electrodeposition was carried out on the $\mathrm{In}_{2} \mathrm{O}_{3}$-coated PET substrate, acting as the working electrode, in a glass cell immersed in a water bath held at $70{ }^{\circ} \mathrm{C}$, with the $\mathrm{Ag} / \mathrm{AgCl}$ electrode and $\mathrm{Pt}$ wire serving as the reference and counter electrodes, respectively. Electrolyte solutions of 0.001 and 0.1 $\mathrm{M} \mathrm{Zn}(\mathrm{NO})_{3} \cdot 6 \mathrm{H}_{2} \mathrm{O}$, mixed with a $0.1 \mathrm{M} \mathrm{KCl}$ supporting electrolyte, were used to obtain $\mathrm{ZnO}$ nanopillars and nanowalls, respectively. An electrochemical workstation was employed to deposit the $\mathrm{ZnO}$ nanostructures by amperometry potentiostatically at $-1.1 \mathrm{~V}$ relative to the reference electrode. Typical deposition times used to grow the nanopillars and nanowalls were 2 and $1 \mathrm{~h}$, respectively. The resulting nanodeposits were thoroughly rinsed in Millipore water and then characterized by a variety of techniques, including field-emission scanning electron microscopy (SEM) and X-ray photoelectron spectroscopy (XPS). The FE measurements were carried out in a parallel-plate diode configuration with a stainless steel rod (1.5$\mathrm{mm}$ diameter) as the anode and the $\mathrm{ZnO}$ nanodeposits as the 


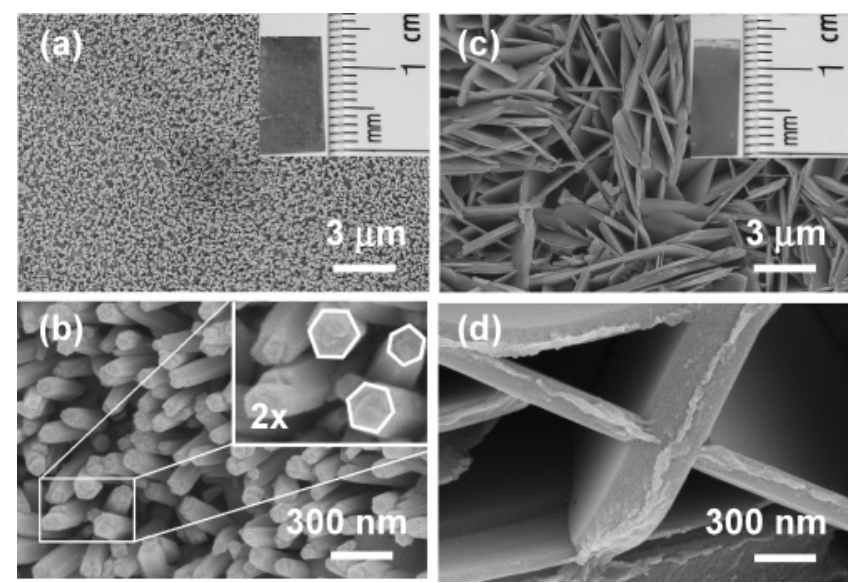

Figure 1. SEM images of (a,b) $\mathrm{ZnO}$ nanopillars and (c,d) nanowalls electrodeposited on $\operatorname{In}_{2} \mathrm{O}_{3}$-coated PET substrates at $70{ }^{\circ} \mathrm{C}$ in 0.001 and $0.1 \mathrm{M} \mathrm{Zn}\left(\mathrm{NO}_{3}\right)_{2} \cdot 6 \mathrm{H}_{2} \mathrm{O}$ solutions, respectively. The insets in $(\mathrm{a}, \mathrm{c})$ show the corresponding photographs of the as-deposited samples, and the inset in (b) shows a magnified image depicting the hexagonal shape of the nanopillars.

cathode, at an anode-to-cathode separation of $0.5 \mathrm{~mm}$, in a base vacuum better than $10^{-6}$ Torr.

\section{Results and Discussion}

Figure 1 shows the morphologies of $\mathrm{ZnO}$ nanopillars and nanowalls grown on $\mathrm{In}_{2} \mathrm{O}_{3}$-coated PET substrates. The asdeposited nanopillar and nanowall samples appear to be reddishgreen and grayish, respectively, as illustrated in the insets of Figure 1. Evidently, uniform deposition of 1D nanopillars with a narrow size distribution (80-100-nm diameter) can be easily achieved at a low $(0.001 \mathrm{M}) \mathrm{Zn}\left(\mathrm{NO}_{3}\right)_{2} \cdot 6 \mathrm{H}_{2} \mathrm{O}$ electrolyte concentration (Figure 1a). The largely vertically oriented nanopillars are of hexagonal shape with a rough top surface (Figure 1b). The inset of Figure $1 \mathrm{~b}$ shows a magnified image depicting the hexagon shape and the rough top surface of the nanopillars. The equivalent diameters of $\mathrm{ZnO}$ nanopillars do not appear to vary along their axes. Recently, Gao et al. reported $\mathrm{ZnO}$ "nanowires" of 200-300-nm diameter with a similar hexagonal shape obtained on gold-coated Kapton polyimide films by using a hydrothermal method at $60-80{ }^{\circ} \mathrm{C}$ with a reaction time of $1-72 \mathrm{~h} .{ }^{18}$ The other $\mathrm{ZnO}$ work involving plastic substrates was reported earlier by Yang et al., ${ }^{19}$ who prepared nanoneedles also on Kapton polyamide substrates at $200{ }^{\circ} \mathrm{C}$ by using an elaborate technique involving filtered cathodic vacuum arc deposition followed by $1-\mathrm{keV}$ Ar ion beam irradiation. The present $\mathrm{ZnO}$ nanopillars on PET substrates therefore represent the only such nanostructures prepared not only by a direct electrodeposition technique but also on a low-cost plastic substrate with a considerably lower thermal tolerance (with an upper working temperature at least $100{ }^{\circ} \mathrm{C}$ lower than polyimide). Like Gao et al., ${ }^{18}$ we can also use the deposition time to control the length and density of the nanopillars in the present work. At a higher $\mathrm{Zn}\left(\mathrm{NO}_{3}\right)_{2} \cdot 6 \mathrm{H}_{2} \mathrm{O}$ concentration $(0.1 \mathrm{M})$, flat 2D wall-like nanostructures, with wall thickness of 100-300 $\mathrm{nm}$ and considerable length of $2-6 \mu \mathrm{m}$, are found to grow nearvertically on the substrate (Figure 1c). The lateral growth of nanowalls appears to cease when one nanowall meets another, often creating compartments (Figure 1d). The present $\mathrm{ZnO}$ nanowalls therefore represent the only $2 \mathrm{D} \mathrm{ZnO}$ nanostructures grown on a plastic substrate reported to date. Of the few reports on $2 \mathrm{D} \mathrm{ZnO}$ nanostructures obtained by low-temperature methods, the nanodisks, ${ }^{20}$ nanoplatelets, ${ }^{21}$ and "nanosheets" 8,22 electrodeposited on ITO-glass or zinc films are found to be
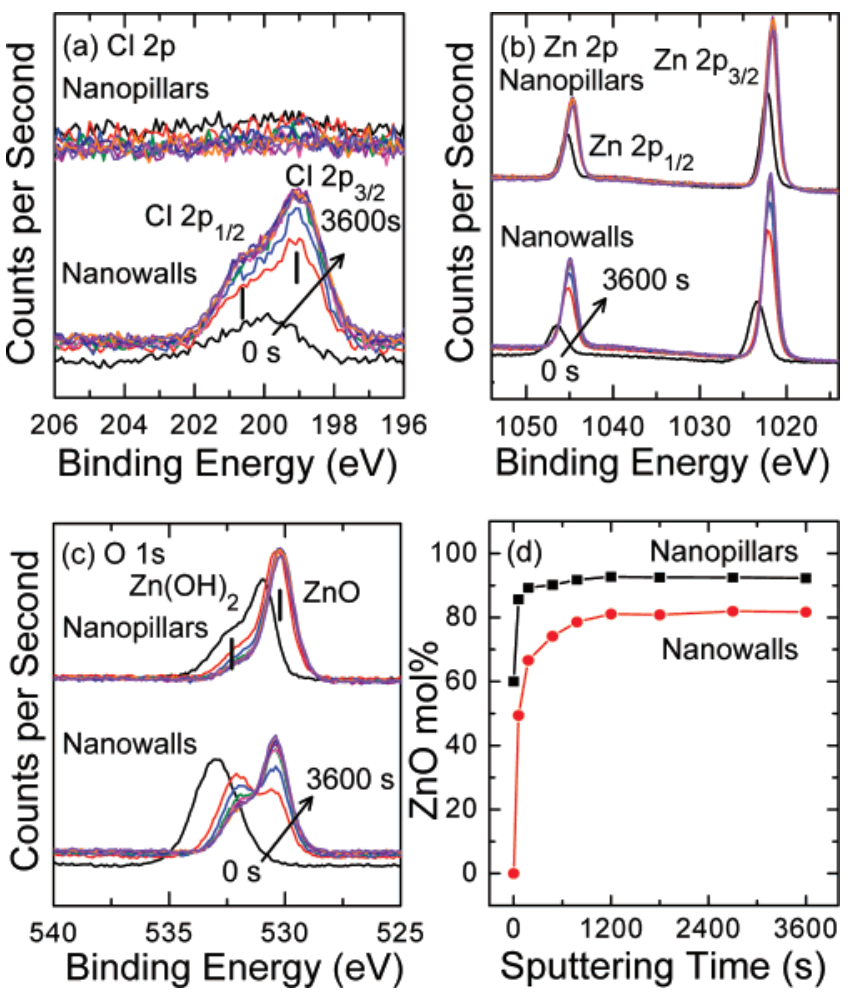

Figure 2. XPS spectra of (a) $\mathrm{Cl} 2 \mathrm{p}$, (b) $\mathrm{Zn} 2 \mathrm{p}$, and (c) $\mathrm{O}$ 1s regions of nanopillars and nanowalls electrodeposited on $\mathrm{In}_{2} \mathrm{O}_{3}$-coated PET substrates at $70{ }^{\circ} \mathrm{C}$ and upon argon ion sputtering for $0,60,180,480$, $780,1200,1800,2700$, and 3600 s. (d) shows the corresponding $\mathrm{ZnO}$ mol $\%$ as a function of sputtering time.

generally flakelike and of hexagonal shape (up to 5- $\mu \mathrm{m}$ diameter). The formation of these $\mathrm{ZnO}$ platelike nanostructures might be due to a lower $\mathrm{Zn}\left(\mathrm{NO}_{3}\right)_{2} \cdot 6 \mathrm{H}_{2} \mathrm{O}$ concentration $(0.05$ $\mathrm{M})$ employed than that used in the present work $(0.1 \mathrm{M})$. In contrast, $\mathrm{Ng}$ et al. ${ }^{16}$ and Lao et al. ${ }^{17}$ have grown nanowalls (with nanowires at the junctions) on a sapphire substrate using gold catalysts in a high-temperature thermal evaporation method above $900{ }^{\circ} \mathrm{C}$. These curtainlike nanostructures are not flat but appear to be curved, flakelike, and are perpendicular to the substrate, forming continuous interconnecting honeycomb networks.

The formation of $1 \mathrm{D}$ or 2D $\mathrm{ZnO}$ nanostructures depends on the underlying growth mechanism, which can be deduced from our XPS spectra collected as a function of the sputtering time (Figure 2). In particular, the $\mathrm{Cl} 2 \mathrm{p}$ spectra (Figure 2a) show the presence of $\mathrm{Cl} 2 \mathrm{p}_{3 / 2}\left(2 \mathrm{p}_{1 / 2}\right)$ at 199.0 (201.0) $\mathrm{eV}$ for only nanowalls and not nanopillars, indicating the direct involvement of $\mathrm{Cl}$ in the 2D growth mechanism. The lower intensity of the $\mathrm{Cl} 2 \mathrm{p}$ feature in the near surface region (corresponding to 0 , 60 , and 180 s sputtering time) of the nanowalls is due to rinsing of the sample after the deposition. $\mathrm{ZnO}$ is well-known to preferentially grow in the (0001) plane, resulting in 1D nanostructure, e.g., nanowires or nanopillars. A more concentrated $\mathrm{Zn}\left(\mathrm{NO}_{3}\right)_{2} \cdot 6 \mathrm{H}_{2} \mathrm{O}$ solution $(0.1 \mathrm{M})$ used for the nanowall deposition enables faster reaction kinetics for the formation of $\mathrm{Zn}(\mathrm{OH})_{2}$ from the $\mathrm{Zn}^{2+}$ and $\mathrm{OH}^{-}$ions. As soon as $\mathrm{Zn}(\mathrm{OH})_{2}$ is dehydrated to form $\mathrm{ZnO}$, the polar (0001) crystal plane of the resulting $\mathrm{ZnO}$ is capped by $\mathrm{Cl}^{-}$ions (from the $\mathrm{KCl}$ supporting electrolyte), which redirects the growth in the second most preferable crystal planes, i.e., (1010) and (0110), forming the observed 2D structures. On the other hand, the kinetics for the hydroxylation reaction is slower in a less concentrated $\mathrm{Zn}$ $\left(\mathrm{NO}_{3}\right)_{2} \cdot 6 \mathrm{H}_{2} \mathrm{O}$ solution $(0.001 \mathrm{M})$ used for the nanopillars 


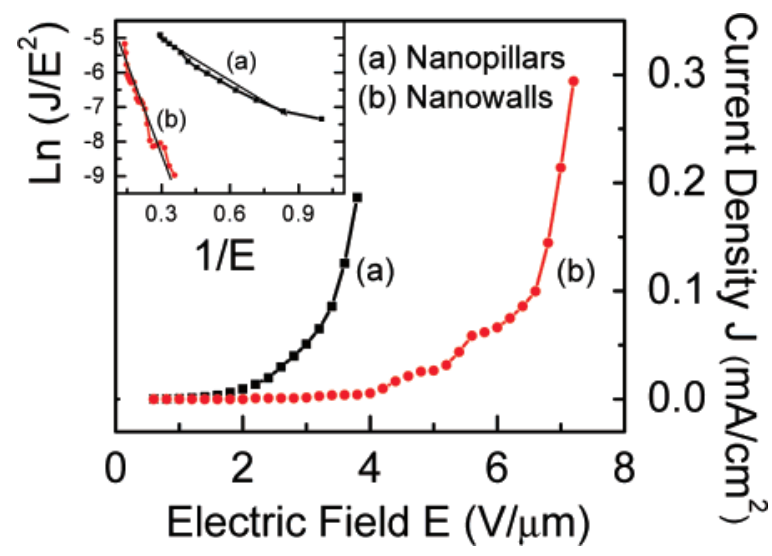

Figure 3. Field-emission $J-E$ characteristics of (a) $\mathrm{ZnO}$ nanopillars and (b) nanowalls electrodeposited on $\operatorname{In}_{2} \mathrm{O}_{3}$-coated PET substrates at $70{ }^{\circ} \mathrm{C}$. The inset shows the corresponding Fowler-Nordheim plots of $\ln \left(J / E^{2}\right)$ versus $(1 / E)$.

growth, which allows the preferred $\mathrm{ZnO}$ growth in the (0001) plane to predominate over $\mathrm{Cl}^{-}$capping. The corresponding preferred growth directions of nanowalls and nanopillars have also been confirmed by our glancing incidence X-ray diffraction measurements (not shown). The capping of the (0001) plane by electronegative ions such as tetrasulfonated metallophthalocyanines and $\mathrm{Cl}^{-}$has been previously proposed for the formation of $\mathrm{ZnO}$ nanodisks ${ }^{20}$ and nanoplates. ${ }^{21}$ The presence of $\mathrm{Cl}$ throughout the nanowalls shown in Figure 2a therefore definitively validates the capping mechanism for the formation of $2 \mathrm{D} \mathrm{ZnO}$ nanostructures. Figure $2 \mathrm{~b}$ shows the corresponding $\mathrm{Zn} 2 \mathrm{p}_{3 / 2}\left(2 \mathrm{p}_{1 / 2}\right)$ feature at 1021.7 (1044.7) $\mathrm{eV}$ for both nanopillars and nanowalls, with the observed spin-orbit splitting of $23.0 \mathrm{eV}$ in excellent accord with the literature value of 22.97 $\mathrm{eV} .{ }^{23}$ The single peak in the $\mathrm{Zn} 2 \mathrm{p}_{3 / 2}\left(2 \mathrm{p}_{1 / 2}\right)$ feature indicates the presence of only the divalent $\mathrm{Zn}$ (II) oxidation state, corresponding to both $\mathrm{Zn}(\mathrm{OH})_{2}$ and $\mathrm{ZnO}$. Figure 2c depicts the respective $\mathrm{O} 1 \mathrm{~s}$ envelops of $\mathrm{ZnO}$ nanopillars and nanowalls, which consist of two components corresponding to $\mathrm{Zn}(\mathrm{OH})_{2}$ at $532.0 \mathrm{eV}$ and $\mathrm{ZnO}$ at $530.2 \mathrm{eV}$, in good agreement with the literature values.. ${ }^{24,25}$ The $\mathrm{Zn}(\mathrm{OH})_{2}$ component is found to weaken while the $\mathrm{ZnO}$ component strengthens with increasing sputtering time, which indicates the presence of a $\mathrm{Zn}(\mathrm{OH})_{2}$ rich surface region. Figure $2 \mathrm{~d}$ shows the respective sputtering profiles of the corresponding $\mathrm{ZnO}$ mole percent, estimated by the area ratio of the $\mathrm{ZnO}$ component to the sum of the $\mathrm{ZnO}$ component and half of the $\mathrm{Zn}(\mathrm{OH})_{2}$ component. Evidently, the $\mathrm{ZnO}$ mole percent for nanopillars is consistently higher than that of nanowalls at each sputtering time. The higher $\mathrm{ZnO}$ mole percent in nanopillars is due to the slower reaction kinetics occurring at a low electrolyte concentration, which allows conversion of most of the $\mathrm{Zn}(\mathrm{OH})_{2}$ to $\mathrm{ZnO}$. At the higher electrolyte concentration used for the nanowall deposition, a sufficient amount of $\mathrm{Zn}(\mathrm{OH})_{2}$ remains unconverted (due to the corresponding faster kinetics), thereby lowering the $\mathrm{ZnO}$ mole percent. It should be noted that the spectral shifts observed at the beginning of the sputtering process (Figure $2 \mathrm{a}-\mathrm{c}$, curves for 0,60 , and $180 \mathrm{~s}$ sputtering time) are due to the removal of nonconducting $\mathrm{Zn}(\mathrm{OH})_{2}$ at the surface of the $\mathrm{ZnO}$ nanodeposits.

Figure 3 shows the emission current density as a function of the applied electric field for nanopillars and nanowalls. The turnon fields of nanopillars and nanowalls are measured to be, respectively, $1.2(2.0 \mathrm{~V} / \mu \mathrm{m})$ and $2.2 \mathrm{~V} / \mu \mathrm{m}(4.2 \mathrm{~V} / \mu \mathrm{m})$ at a current density of $1 \mu \mathrm{A} / \mathrm{cm}^{2}\left(10 \mu \mathrm{A} / \mathrm{cm}^{2}\right)$. The slightly higher turn-on field observed for nanowalls than that of nanopillars is likely caused by the larger dimensions of the nanowalls (with a ledge thickness of $100-300 \mathrm{~nm}$ ) than nanopillars (with diameters of $80-100 \mathrm{~nm}$ ) and by the lower electric field density at the nanowall ledges than the nanopillar tips. Furthermore, the observed turn-on fields from both nanopillars and nanowalls on PET substrates are found to be lower (i.e., better) than the majority of $\mathrm{ZnO}$ nanostructures deposited on $\mathrm{Si}$ or other metallic substrates, including the $\mathrm{ZnO}$ nanowire arrays $(3.9 \mathrm{~V} / \mu \mathrm{m}$ at 1 $\left.\mu \mathrm{A} / \mathrm{cm}^{2}\right),{ }^{6}$ nanowires $\left(9.5-16.9 \mathrm{~V} / \mu \mathrm{m}\right.$ at $\left.10 \mu \mathrm{A} / \mathrm{cm}^{2}\right),{ }^{8}$ and nanotubes $\left(7.0 \mathrm{~V} / \mu \mathrm{m} \text { at } 0.1 \mu \mathrm{A} / \mathrm{cm}^{2}\right)^{9}$ prepared by using electrochemical or hydrothermal methods. The turn-on fields are also lower than those of $\mathrm{ZnO}$ nanorods $(2.3 \mathrm{~V} / \mu \mathrm{m}$ for 1 $\left.\mu \mathrm{A} / \mathrm{cm}^{2}\right){ }^{26}$ nanoneedles $\left(4.1 \mathrm{~V} / \mu \mathrm{m}, 1.8 \mathrm{~V} / \mu \mathrm{m}\right.$ for $\left.1 \mu \mathrm{A} / \mathrm{cm}^{2}\right),{ }^{19,27}$ and nanonails $\left(3.8 \mathrm{~V} / \mu \mathrm{m} \text { for } 0.1 \mu \mathrm{A} / \mathrm{cm}^{2}\right)^{28}$ obtained by thermal evaporation methods. The inset of Figure 3 shows the corresponding Fowler-Nordheim $(\mathrm{F}-\mathrm{N})$ plot. The field enhancement factor " $\beta$ " is calculated from the slope of the straight line on the $\mathrm{F}-\mathrm{N}$ plot, with the work function of $\mathrm{ZnO}$ taken to be 5.3 $\mathrm{eV} .{ }^{9}$ The estimated $\beta$ value for nanopillars (23 104) is found to be substantially higher than that for nanowalls (5256), which is also consistent with the lower turn-on field observed for the nanopillars. Moreover, the $\beta$ values for nanopillars and nanowalls obtained in the present work are comparable to and at the higher end of those reported for other $\mathrm{ZnO}$ nanostructures. ${ }^{1,2,26}$ The electron FE process is known to depend on several factors, including the geometrical parameters such as the aspect ratio (that is directly related to the field enhancement factor) and defects of the emitter material, as well as the ohmic contact between the emitter material and the substrate. The large $\beta$ value observed for nanopillars in the present work therefore suggests that nanopillars are potentially superior FE materials. The low temperature employed in the present work generally favors the formation of lattice defects (due to the oxygen/zinc deficiency), and the resulting nanostructures are therefore expected to exhibit better FE performance. In addition, the FE properties can be further enhanced by depositing a metallic interlayer (e.g., Au/ Ti) to improve the ohmic contact between the emitter material and the substrate, as recently demonstrated by Park et al. ${ }^{5}$ It should be noted that the FE performance of the present $\mathrm{ZnO}$ nanostructures are lower than the carbon nanotubes (CNTs), generally known to be a good emitter. In particular, the turn-on field (at $1 \mu \mathrm{A} / \mathrm{cm}^{2}$ ) and the threshold field (at 10 $\mathrm{mA} / \mathrm{cm}^{2}$ ) for CNTs are found to be less than 1 and $5 \mathrm{~V} / \mu \mathrm{m}$, respectively. ${ }^{29-31}$ The turn-on field that we obtain for the $\mathrm{ZnO}$ nanostructures in the present work is in the range of $1-3 \mathrm{~V} / \mu \mathrm{m}$, and the corresponding threshold field could be higher than 5 $\mathrm{V} / \mu \mathrm{m}$. The lower performance is believed to be due to the larger diameter of individual $\mathrm{ZnO}$ nanopillars $(\sim 100 \mathrm{~nm})$ than CNTs $(<20 \mathrm{~nm})$ and to the lower conductivity of $\mathrm{ZnO}$ nanostructures than CNTs. While Cheng et al. have reported a higher emission stability for $\mathrm{ZnO}$ nanoneedles over CNTs, suggesting that $\mathrm{ZnO}$ nanostructures could be a more reliable emitter material, ${ }^{32}$ more studies are clearly needed to further improve the aforementioned physical properties of these nanostructured $\mathrm{ZnO}$ emitters.

\section{Conclusions}

We have demonstrated successful growth of both 1D (nanopillars) and 2D (nanowalls) $\mathrm{ZnO}$ nanostructures on $\mathrm{In}_{2} \mathrm{O}_{3}$-coated PET substrates at $70{ }^{\circ} \mathrm{C}$ by using electrodeposition. Our XPS depth-profiling study shows the direct involvement of $\mathrm{Cl}^{-}$ions, providing strong support for the capping mechanism in the formation of $\mathrm{ZnO}$ nanowalls. A lower turn-on field is obtained for nanopillars than nanowalls, which is attributed to their smaller dimensions (diameters) and considerably larger $\beta$ value and to a higher field density at the tips. The turn-on fields from 
both the nanowalls and nanopillars are found to be lower than not only all the reported $\mathrm{ZnO}$ nanostructures obtained by electrochemical or hydrothermal techniques but also a majority of nanostructures obtained by thermal evaporation methods. The present $\mathrm{ZnO}$ nanostructures obtained on flexible PET substrates are therefore good candidates for low-cost, large-area display applications. The simple electrodeposition method, as demonstrated on a plastic substrate with a low working temperature (such as PET) in the present work, promises a powerful technique to fabricate $\mathrm{ZnO}$ nanostructures on other flexible substrates appropriate for solar cells, flexible electronics, and other applications.

Acknowledgment. This work is supported by the Natural Sciences and Engineering Research Council of Canada, and the Japan Society for the Promotion of Science (Grants-in-aid for Scientific Research No. 18560661).

\section{References and Notes}

(1) Jo, S. H.; Banerjee, D.; Ren, Z. F. Appl. Phys. Lett. 2004, 85, 1407.

(2) Wang, W.; Zeng, B.; Yang, J.; Poudel, B.; Huang, J.; Naughton, M. J.; Ren, Z. Adv. Mater. 2006, 18, 3275.

(3) Xu, C. X.; Sun, X. W. Appl. Phys. Lett. 2003, 83, 3806.

(4) Ye, C.; Bando, Y.; Fang, X.; Shen, G.; Golberg, D. J. Phys. Chem. C 2007, 111, 12673.

(5) Park, C. J.; Choi, D. K.; Yoo, J.; Yi, G. C.; Lee, C. J. Appl. Phys. Lett. 2007, 90, 83107.

(6) Xu, C. X.; Sun, X. W.; Fang, S. N.; Yang, X. H.; Yu, M. B.; Zhu, G. P.; Cui, Y. P. Appl. Phys. Lett. 2006, 88, 161921.

(7) Yang, C. J.; Wang, S. M.; Liang, S. W.; Chang, Y. H.; Chen, C.; Shieh, J. M. Appl. Phys. Lett. 2007, 90, 033104.

(8) Cao, B.; Teng, X.; Heo, S. H.; Li, Y.; Cho, S. O.; Li, G.; Cai, W. J. Phys. Chem. C 2007, 111, 2470

(9) Wei, A.; Sun, X. W.; Xu, C. X.; Dong, Z. L.; Yu, M. B.; Huang, W. Appl. Phys. Lett. 2006, 88, 213102.

(10) Liu, J.; Huang, X.; Li, Y.; Ji, X.; Li, Z.; He, X.; Sun, F. J. Phys. Chem. C 2007, 111, 4990.

(11) Pauporte, T.; Lincot, D.; Viana, B.; Pelle, F. Appl. Phys. Lett. 2006, $89,233112$.
(12) Yang, J.; Liu, G.; Lu, J.; Qiu, Y.; Yang, S. Appl. Phys. Lett. 2007, 90,103109 .

(13) Anthony, S. P.; Lee, J. I.; Kim, J. K. Appl. Phys. Lett. 2007, 90, 103107.

(14) Huo, K.; Hu, Y.; Fu, J.; Wang, X.; Chu, P. K.; Hu, Z.; Chen, Y. J. Phys. Chem. C 2007, 111, 5876

(15) Yang, Y. H.; Wang, B.; Xu, N. S.; Yang, G. W. Appl. Phys. Lett. 2006, 89,043108

(16) Ng, H. T.; Li, J.; Smith, M. K.; Nguyen, P.; Cassell, A.; Han, J.; Meyyappan, M. Science 2003, 300, 1249.

(17) Lao, J. Y.; Huang, J. Y.; Wang, D. Z.; Ren, Z. F.; Steeves, D.; Kimball, B.; Porter, W. Appl. Phys. A 2004, 78, 539.

(18) Gao, P. X.; Song, J.; Liu, J.; Wang, Z. L. Adv. Mater. 2007, 19 , 67.

(19) Yang, H. Y.; Lau, S. P.; Yu, S. F.; Huang, L.; Tanemura, M.; Tanaka, J.; Okita, T.; Hng, H. H. Nanotechnology 2005, 16, 1300.

(20) Yoshida, T.; Tochimoto, M.; Schlettwein, D.; Woehrle, D.; Sugiura, T.; Minoura, H. Chem. Mater. 1999, 11, 2657.

(21) Xu, L.; Guo, Y.; Liao, Q.; Zhang, J.; Xu, D. J. Phys. Chem. B 2005, 109, 13519

(22) Kar, S.; Dev, A.; Chaudhuri, S. J. Phys. Chem. B 2006, 110, 17848

(23) Moulder, J. F.; Stickle, W. F.; Sobol, P. E.; Bomben, K. D. In Handbook of X-ray Photoelectron Spectroscopy; Chastain, J., Ed.; PerkinElmer Corp.: Waltham, MA, 1992.

(24) Bär, M.; Reichardt, J.; Grimm, A.; Kötschau, I.; Lauermann, I.; Rahne, K.; Sokoll, S.; Lux-Steiner, M. C.; Fischer, C. H.; Weinhardt, L.; Umbach, E.; Heske, C.; Jung, C.; Niesen, T. P.; Visbeck, S. J. Appl. Phys. 2005, 98, 053702

(25) Puchert, M. K.; Timbrell, P. Y.; Lamb, R. N. J. Vac. Sci. Technol. A 1996, 14, 2220.

(26) Li, C.; Fang, G.; Liu, N.; Li, J.; Liao, L.; Su, F.; Li, G.; Wu, X.; Zhao, X. J. Phys. Chem. C 2007, 111, 12566.

(27) Yu, K.; Zhang, Y. S.; Xu, R. L.; Ouyang, S. X.; Li, D. M.; Luo, L. Q.; Zhu, Z. Q.; Ma, J.; Xie, S. J.; Han, S. H.; Geng, H. R. Mater. Lett. 2005, 59, 1866.

(28) Xu, F.; Yu, K.; Li, Q.; Zhu, Z.; Yao, T. J. Phys. Chem. C 2007, 111,4099

(29) Fujii, S.; Honda, S.; Machida, H.; Kawai, H.; Ishida, K.; Katayama, M.; Furuta, H.; Hirao, T.; Oura, K. Appl. Phys. Lett. 2007, 90, 153108.

(30) Jo, S. H.; Wang, D. Z.; Huang, J. Y.; Li, W. Z.; Kempa, K.; Ren, Z. F. Appl. Phys. Lett. 2004, 85, 810.

(31) Lyth, S. M.; Hatton, R. A.; Silva, S. R. P. Appl. Phys. Lett. 2007, 90, 013120

(32) Cheng, A. J.; Wang, D.; Seo, H. W.; Liu, C.; Park, M.; Tzeng, Y. Diamond Relat. Mater. 2006, 15, 426. 